\title{
A Hacking Atlas: Holistic Hacking in the Urban Theater
}

\author{
Douglas Schuler
}

\begin{abstract}
This essay is intended to help further the understanding of contemporary social change and social activism, which in turn should assist people developing civic intelligence within both local and global communities. Civic intelligence is a social phenomenon that describes how well collectivities address their shared problems efficiently and equitably. It describes examples at a variety of scales from a neighborhood trying to stop a new trash incinerator from being built next to its school to the global climate change agreement negotiated in Paris in 2015. To accomplish this effort, the concepts of hacking and holistic hacking, and hacking spaces (and seven types of hacking spaces) are introduced and then employed in relation to an actual activist mobilization called Shell No, that was waged in Seattle by environmental activists over a 30-day period in Spring 2015.
\end{abstract}

Keywords Civic intelligence $\cdot$ Activism $\cdot$ Hacking $\cdot$ Holistic hacking Hacking spaces $\cdot$ Governance $\cdot$ Social change $\cdot$ Cities $\cdot$ Enablers $\cdot$ Hackability Coordination

\section{Introduction}

This essay is intended to help further the understanding of contemporary social change and social activism, which in turn should assist people developing civic intelligence within both local and global communities. To accomplish this, the concepts of hacking and holistic hacking, and hacking spaces (and seven types of hacking spaces, each described below) are introduced and then employed in relation to an actual activist campaign. Generally speaking, a hack is a single action or intervention; they are insufficient for bringing about significant changes. Holistic hacking describes the phenomenon in which a variety of hacks that are not planned or dic-

D. Schuler $(\bowtie)$

The Evergreen State College \& The Public Sphere Project, 2202 N. 41st Street,

Seattle, WA 98103, USA

e-mail: douglas@publicsphereproject.org

(C) The Author(s) 2019 
tated by a single source are sufficiently coordinated that they help bring about a common goal. Civic intelligence, the focus of my work for nearly 20 years, helps to provide purpose and substance to our considerations of hacking and holistic hacking. Civic intelligence is a social phenomenon that describes how well collectivities address their shared problems efficiently and equitably. It describes examples at a variety of scales from a neighborhood trying to stop a new trash incinerator from being built next to its school to the global climate change agreement negotiated in Paris in 2015. The last piece of our analytic framework, hacking spaces, describes collections of people, roles, rules, norms, processes, etc., that can influence how city-making plays out. We discuss seven types of spaces specifically as they relate to cities. Each of the spaces, although not wholly autonomous, provides a sort of governance, formal or informal, that determines a portion of the maintenance of the status quo and the ability to help determine the direction of the whole. Each of the seven spaces describes spheres of action that interact with the others. The spaces describe the various sub-theaters within the broader urban theater. The spaces can be used generically in considering the city in the twenty-first century, but here we consider one mobilization, a focused climate action campaign called Shell No, in Seattle waged by environmental activists over 30 days in Spring 2015. Finally, the atlas here, as with more conventional atlases, is a collection of the various spaces, demonstrating how the interconnections of the various actions or hacks can become something resembling holistic hacking.

\section{The City}

People live and die, work and play, suffer and rejoice in cities. And the city is the seat of the economic and cultural engines that drive much of the human activity (and consequently non-human activity, the climate, etc.) on our planet, the urban and the non-urban. The city is a dynamic physical complex of streets, buildings, tunnels, bridges, and complex systems that supply humans with water and electricity and move our wastes invisibly away from many of us. The city is also comprised of an assortment of social and human (and other life) systems that interact with it. It is in a perpetual state of decay, repair, maintenance, and creation. As Lewis Mumford reminds us, "The city creates the theater and is the theater" (1996). This means that the city is open for appropriation, enactment, annotation, occupation, exploration, and hacking.

\section{Hacking and Holistic Hacking}

In general, hacking can be summed up as undisciplined, clandestine, unexpected, unorthodox, volunteer-based, fun, unauthorized, amateur, out of bandwidth, off the grid, skunkworks, not official, experimental, insurgent, out of jurisdiction, transgres- 
sive, free, DIY, and provisional. Thus, hacking can be seen as oppositional to the bureaucratic, rationalistic, business-as-usual approach. For that reason, the idea of 'hacking' can serve both as a metaphor and as a pragmatic approach for rooting out opportunities for clever activism in the urban theater.

The urban theater metaphor needs to be briefly introduced and explained further. We use it primarily as a setting for action (similar to its use in military parlance) while acknowledging the importance of the imaginative, performed nature of city life. When the city becomes the theater, the play spills out beyond the theater walls and it is performed throughout the city; the city simultaneously becomes a theater where meaningful actions - sanctioned and non-sanctioned - are enacted and viewed. The roles of actors and audience members tend to shift, they are dynamic and somewhat interchangeable, and their actions are both scripted and improvised. (And, of course, 'actors' are not always human actors; within the city, the buildings, roads, traffic lights, communication systems, are also players....)

The connotations of hacking come in many flavors. One in general circulation goes something like this: illegally breaking into a computer system generally with the intent of causing mischief_-stealing private information or trade or national secrets or causing damage of some sort. The original version basically meant messing around, sometimes obsessively, with computers, programming, and data-generally on tasks that were not on the formal agenda, tasks that were selected solely because they were interesting to the hacker. (See Weizenbaum (1976) and Levy (2001) for two somewhat different versions.) The meaning I employ here is related to 'civic hackers' (Townsend 2013) which generally means using digital approaches for civic amelioration of some sort, often in a non-corporate sense and often with data that been made available with today's transparency initiatives and demands.

For the purposes of this chapter, we are restricting our usage to social or civic amelioration which often includes oppositional actions of one type or another. At the same time, although we are placing most of our attention here on ICT and digital media, we are opening up the idea of hacking to be any type of interruption that shares the attributes discussed above which often, although not always, employs technology of some sort. The general concept that of interrupting the flow is not limited to computing. Similar ideas crop up in a variety of fields including design (Hartmann et al. 2008), fashion (von Busch 2008), art (Guerrilla Girls 1998), technological pranks at sporting events, ${ }^{1}$ and activism (tactical media, message corrections, guerrilla theater, detournement, etc.

Hacking also means plunging right into a project (often writing code) without the benefit (sometimes questionable) of a mock-up, design document, public hearing, or deep analysis. Hacking can be precise and planned yet it is often ad-lib, ad hoc. Hacking at some level is a matter of economy. An 'efficient' or successful hack means a high yield per input: more publicity or support for the hackers' side and/or more pain for the opposition in the form of confusion, embarrassment or discomfort, or embroilment in a more complex, protracted, wider (e.g., becoming involved in legal

\footnotetext{
${ }^{1}$ See, for instance, https://en.wikipedia.org/wiki/Hacks_at_the_Massachusetts_Institute_of_ Technology.
} 
battles) or more costly enterprise. People hack because they're strapped for resources (including time) that may never come. Also, there's something in the nature of a hack that suggests - or at least allows for-experimentation and incremental and improvised adjustments, something that a full-scale plan (e.g., to land a person on the moon and bring him back safely) generally discourages.

Hacking is often conducted sporadically and perpetrated by an individual or small, often marginalized, groups. Often deemed a provocation or a symbolic act, de Lange and de Waal (2013) point out that artistic and other urban interventions (what we might call hacks) often "remain highly temporary and stick to oppositional politics." They argue for an alternative approach to "urban design with digital technologies that focuses on the active role of citizens and uses the city itself as the test bed for experiments." Of course, whether an action is an experiment or not is to some degree in the eye of the beholder. The political moments described by Becher (2012) are unlikely to be considered explicitly as experiments by the activists themselves. And many activist hackers might find the experimental perspective alien, sterile, or confining even though they are certainly involved in some type of informal or implicit evaluation or metacognition (Schuler 2015) regarding the impact of their actions.

A hack can also be a provocation; it is at least intended to suggest a deflection from the business-as-usual path that inertia suggests is the most likely. Humor is a natural hack since it can often be employed economically without necessarily needing vast resources. And while humor by itself is only one hack among many, its role in revealing the flimsy veneer of one imaginary can be invaluable in the construction of an imaginary (or myth or paradigm or vision) that embodies sustainability and social justice. It can play the important role of exposing the rhetoric or imaginary (Wright et al. 2013) that being employed to justify or rationalize the unexamined momentum of the status quo of the present or some version of the status quo of the past. ${ }^{2}$

\subsection{Holistic Hacking and Civic Intelligence}

So far, we have concentrated here on 'hacks'-limited interventions that may require fewer resources - but with an eye toward holism, toward significant and durable social change. Holistic hacking suggests another level of hacking, a concept that is related to civic intelligence, the capability of people working together to address shared concerns equitably and effectively (Schuler 2001). Holistic hacking is intended to be focused on the common good; it is a version or extension of civic hacking. As the name suggests, holistic hacking is more systemic, coordinated, and purposeful than the interventions described above by de Lange and de Waal or by a random, non-coordinated, or economically or politically self-serving hack. The hacks become holistic when one hack helps increase the likelihood that other purposeful

\footnotetext{
${ }^{2}$ This can be exemplified by the curious, imprecise, and somewhat ominous slogan of current president Donald J. Trump: Make America Great Again! Just what period of time was he alluding to? And people who were oppressed during that unnamed period might not agree.
} 
actions (including hacks) that get closer to the goal are now more easily enacted. Significantly, building the capacity of one's allies is one way of getting closer to their goals. Holistic hacking describes a purposeful application of hacks with the spaces that are relevant, positively or negatively, to a desired outcome or set of outcomes. The relevance can be potential or actual. Because the actors have similar goals but different philosophies, norms, strategies, and tactics, they will need to strategically adapt to each other and to changing circumstances if they are to achieve their goals. Holistically hacking the city allows us to bridge the gap between temporary probes and long-lasting effects. A series of temporary hacks could help lead to long-lasting social change-if the hacks were timely, purposeful, capacity-building, and coordinated. Holistic hacking can be done to interject new ideas or focus, and this can be in service of maintenance or upkeep of the city-the everyday re-making of cities as well as the more revolutionary making of cities.

The working hypothesis (and preliminary findings) suggest that a focus on social and environmental amelioration will promote different actions and outcomes than a putatively objective, norm-free enterprise, i.e., that there are general characteristics that distinguish collective intelligence (Malone et al. 2009) and civic intelligence (Schuler 2014, 2015). ${ }^{3}$ As an example of civic intelligence, holistic hacking will necessarily rely on the same enablers, the characteristics of civically intelligent actions to help lead to successful outcomes, that civic intelligence relies on. In other words, some subset of these enablers will be required for successful changes within any of the spaces that constitute the urban theater mentioned by Mumford (1996) in the next section. These enablers, of which nearly 50 have now been identified, have been organized into a framework containing five dimensions (Schuler 2014), namely:

- Knowledge, including a variety of knowledge-based enablers such as theory, knowledge of problems, skills, resources, self-knowledge, and metacognition (the ability to think about one's own thinking);

- Attitude and aspiration, including a variety of enablers that are typically seen as non-cognitive but are essential for civic intelligence such as values, social critique, civic purpose, and self-efficacy;

- Organizational capital, including the processes and structure of the collectivity that are needed to complete tasks effectively, such as personnel, work practices, and access to resources;

- Relational and social capital, including reputation, social networks, social capital, and opportunities; and

- Financial and material resources, including money, buildings, land, and the like.

The framework is used to depict the wide diversity of enablers that are involved in positive social change via civic intelligence. The framework is descriptive as it is really just a list of what sorts of resources (very broadly considered) are useful for civically intelligent activism. The framework can also be used prescriptively. An

\footnotetext{
${ }^{3}$ It is interesting to note that a study of civic intelligence must necessarily include a study of civic ignorance (Proctor and Schiebinger 2008) which, as with civic intelligence, relies on a variety of interrelated processes to sustain it.
} 
organization, for example, could use the framework for self-diagnostics. It could reveal weaknesses within the organization which could then take corrective actions to improve one or more of the enablers by making it more appropriate to the organization's challenges and opportunities.

Each major dimension of the framework will necessarily be engaged in any meaningful action. The important question to ask, however, is how well and to what degree the dimension was engaged. If, for example, a group created a website that contained policy proposals, but the developers had neglected to consult the policy experts within their own group, they would have shown a deficiency in at least three of the five dimensions: knowledge, organizational capital, and resources. This of course also holds true for the individual enablers. Finally, although the enablers are numerous, the list is still not exhaustive-and probably would never be broad enough to cover all circumstances.

\section{Hacking Spaces}

According to historian and urbanist Lewis Mumford, "It is in the city, the city as theater, that man's more purposive activities are focused, and work out, through conflicting and cooperating personalities, events, groups, into more significant culminations" (1996). Social change is complex-it is an ecosystem where people and organizations with varying skills, tactics, and perspectives collaborate often with limited explicit communication and coordination; yet they are working 'together' toward similar ends. The process unfolds over time-and although there are many important patterns to be recognized (and respected), social change cannot be scheduled or engineered, taken for granted, or permanent. This chapter fits within that tradition by presenting seven spaces in which these unfoldings occur, within the context of the city theater. The concept of spaces is used by a variety of disciplines and is fundamental to geography. Its virtues include flexibility and universality. Aase in his article on Symbolic Space (1994) stresses that space must be considered contextually. In this article, the context can be seen generally in terms of urban activism-specifically environmental activism in Seattle during one month of Spring 2015. Harvey and Davidson (1973) stress the usefulness of the concept: “... space becomes whatever we make of it during the process of analysis rather than prior to it." Here, hacking spaces describe a conceptual realm or category that can be fairly readily be demarcated from the other spaces in its universe, basically by the actions within the space, the players, rules, products or results, and goals.

These particular spaces were identified via examination of significant activities that take place within cities using the lens of spaces. We are differentiating between spaces generally by what takes place within them. In other words, different actors give different performances for different purposes using different rules. Generally, this will include norms, values, demographics, actions, and consequences. Contrariwise-when sets of actors and actions are sufficiently different (via demographics, norms, etc.) from other sets-they are likely to be constituting a different space. But 
these spaces are not autonomous: activities within a space can shape (or create or destroy) other spaces or aspects within them.

The seven broad conceptual spaces in which urban hacking can occur correspond to the characteristics of an actual city and to the actual events and issues within that city and those that affect that city. The spaces have diverse sites, actors (including hackers), and areas of focus, modes of actions, and effects. (And the spaces have spaces within them.) The spaces are intended (and hoped) to be comprehensive in that the set of spaces listed here adequately describes (or at least suggests) all of the possible conceptual 'homes' for holistic urban hacking.

The spaces in this 'atlas' are abstract; they become relevant when they are instantiated and mapped to the specific relevant attributes of the city and the issues that are under contention. When considering actual locations within the city as a focus for physical action, there are many options: The location for a demonstration against a war might best be at federal or national state building, demonstrating against redlining might best be done near the entrance of the bank's headquarters; demonstrating against air pollution - which although diffuse is generally far worse in low-income neighborhoods - might be more effective when others are brought to the neighborhood either in person, or virtually, via an online video or a virtual reality tour.

The spaces take particular significance when multiple ones are in play (see the Shell No example below) and when hacking in one space promotes successful hacking and actions in other spaces. How readily an actual city can be 'hacked'-its hackability-will depend on the particular aspects of the city and the skills, creativity, and dedication of the hackers and the hacks they can identify and employ, as well as access to the space. An analysis of the various spaces could also be rich and potentially productive.

Can 'hackability' be operationalized, assessed, perhaps even measured, and calculated? Although the idea is currently underdeveloped, the spaces could be queried for measures of hackability. One important note on our hypothetical hackability index is that it is not intended to be an index of vulnerabilities, although an authoritarian government could think of it in those terms. The hackability index in many ways could be thought of as an index of openness and opportunities - and any closing of them or raising the cost of using them could be considered as threats to the open character of the city - and its various spaces.

Just as traditional maps of physical spaces can be organized via political, topological, or other means that highlight some characteristics and downplay others, these seven spaces bring particular focus to some attributes at the expense of others. And, like maps of physical cities, the perspectives of spaces where political boundaries and natural features such as rivers are likely to be strongly related, the spaces in the hacking atlas are likewise strongly and densely interconnected. The hope is that the conceptual slicing and dicing of the city in a very broad sense can contribute to our social imagination, both practically and theoretically. 


\subsection{Information and Communication Space}

While today's civic hacking has little in common with the idea of hacking a competitor's computer system or stealing personal data and identity, the legacy of this reliance on hidden data is often still present in today's usage: using digital data that has been kept out of reach of citizens, or, even, repurposing data for purposes that the people who collected the data did not foresee, or might even oppose, still remain. Information and communication can often provide the seed for other types of hackings. The space also includes vital elements of the economic side of the city. John Perry Barlow's comment that "cyberspace is where your money is" highlights the fact that financial information is stored in 'cyberspace' and online systems are responsible for massive amounts of financial transfers. Thus, cyberspace provides the target for both hackers that are providing information about corruption and money-laundering and also for the people who would like to add the money in your account to the money in their account.

How the 'hackers' within a social movement or urban campaign communicate with each other and with potential allies is important as well-and the security of these channels can be vital. This area of course is the focus of many articles and discussion thanks in part to new movements like Arab Spring (Lotan et al. 2011) and the Occupy Movement (Gamson and Sifry 2013). New DIY networks that can be set up and mobilized easily and autonomously without being connected to the Internet also offer opportunities for hacking in this space (Antoniadis and Apostol 2014). It is also important to note that the mass media is covered in this space [which is similar to mediascapes (Appadurai 1990)]. The mass media can act as a force multiplier for the hack, but, so too, can email, electronic petitions, or social media. And because the mass media often comes with its own agenda, it is often necessary to hack this as well. See the patterns on Illegitimate Theater, Tactical Media, Indigenous Media, or Media Intervention (all in Schuler 2008) for a variety of perspectives on media interventions. Civil society has been active in this space. Community networks (Schuler 1996) generally created and maintained by community developers and activists to support local community using the Internet numbered in the hundreds before commercial interests became dominant.

\subsection{Governance Space}

This space describes the formal governmental procedures that are intended to govern the city and the seven spaces within it. And while these procedures are not necessarily always obeyed (by either the governed or the governors), may be subject to bribes and corruption or other unequal application, or be inconsistent or unfathomably complex, the influence of this space is generally quite considerable as it is backed up by laws, judges, police, and prisons. For this reason, a hack that helps enlist a part of the government (e.g., the legal system) in the struggle can be considerably powerful. The 
'checks and balances' that have been intentionally built into democratic systems (by early adopters of cybernetics and systems thinking) — as well as the polycentric reach and roles of governmental bodies (Ostrom 2015)_-suggest that myriad points exist for holistic hacking and that the potential of enlisting formal governmental systems in social struggles is possible. The boundaries of this space (like the others) are not constant. The entire space can change fundamentally, although more frequently this change is more localized. It is subject to some renegotiation, readjustment, and realignment in which 'ordinary' citizens are granted some quasi-governmental status. This can be seen in institutions such as citizen advisory boards and public meetings. One important hack is establishing a citizen police review board—or changing it by adding more representative voices from the community it polices.

To be effective in this space, some important questions need to be addressed. Where are various types of decisions made_-and how are they made — and by whom? Government agencies come in many shapes and sizes and have a variety of roles and responsibilities that connect with each other-and with citizens-in complex ways that are not well understood by the citizenry [or, even, in many cases, by the officials themselves (Buxbaum 2015)]. Knowledge of this space-where responsibilities and decision making are situated — while not hacking in its own right, provides important insights about where to hack. Hacking in this space includes any type of reconfiguration of the roles of government and citizens. Participatory budgeting-hacking the budget-is a major new development in this area because it opens up the role of budgeting to include people who played little direct role historically-citizens. See Stortone and De Cindio (2015) for an online instantiation of this process. The governance space also includes the idea of self-governance and protocols such as Roberts Rules of Order (Robert et al. 2011) belong here as well as new online versions such as eLiberate which supports distributed decision making using Roberts Rules of Order in an online environment (Schuler 2009).

\subsection{Social, Organizational, and Institutional Space}

While the space above is specifically related to the formal institutions of government and its relationship with people, this space is associated with civil society including social networks (both 'traditional' and online), advocacy, educational, community, social, and organized labor. The MAZI is an interesting case study of an 'institutional' effort to reach out to activists and support grassroots movements and bottom-up initiatives through a 'research and action' funding framework (see Research and Action pattern). ${ }^{4}$ Hacking in this space might mean starting a new organization, joining an existing one, or, even, devising a new type of organization as people did when they developed the 'B Corporation' 5 entity or a bottom-up 'world citizen parliament' (Schuler 2013). It might mean developing new partnerships, consortiums,

\footnotetext{
${ }^{4}$ See http://mazizone.eu.

${ }^{5}$ See https://en.wikipedia.org/wiki/B_corporation.
} 
coalitions, etc., that are able to organize themselves to create larger actions on more fronts. This is a form of social network hacking - and it doesn't only pertain to online social networks.

Although much of the activity within the space seems to be more hostage to inertia than others, there is room for hacking. One way is to remind organizations of their founding goals or mission-either to help activate a new line of work for them or to embarrass them for their dereliction of duty. One interesting approach along these lines was demonstrated a few years ago when activists in 1998 formally requested the Attorney General of California to revoke the charter of a US corporation, Union Oil Company of California, which is the legal basis for a corporation's right to exist (Brooks 1998) for actions that were deemed to be illegal.

\subsection{Infrastructure Space}

Cities in particular are noted by various socio-technological infrastructures that maintain them. Energy use, surveillance, water availability, and quality, etc., are related to this space. This space can be hacked in many ways from hooking into the electrical grid without paying to setting up a free wireless network. These infrastructures are largely invisible, in the sense that people may use them routinely but rarely think about how they work, how they are maintained, etc. This allows city dwellers to pay attention to other things, but it also helps sustain a level of civic ignorance: How are citizens expected to contribute to infrastructure decisions-let alone develop alternatives-in a city if they lack basic knowledge? One hack here is simply making infrastructures more visible. The Local Governments for Sustainability (iclei.org) provides some window into this world although it is relatively static at this point, while an ensemble of more dynamic, real-time (and other) displays would be more illustrative and useful. The smart city movement, primarily an industry initiative, is positioned as a solution to concerns over sustainability. These 'smart cities' are to be managed to a very large degree via an intelligent use of big data. Although there is likely to be substantial potential with this approach, the momentum is generally away from transparency, citizen sovereignty, and self-governance and toward technocracy and inscrutability of infrastructure.

Numerous opportunities exist for new civic infrastructure, such as municipal broadband, community networks, or deliberation systems. Setting up a new electrical utility corporation could also be considered a type of systemic or long-term hack - one that could also be considered as a part of another space (such as organizational and institutional space). And any effort to improve infrastructure within a city can be an occasion for hacking. And although infrastructure space can (somewhat justifiably) be seen as big, expensive, impersonal, and severely limited in type, this is not necessarily the case. Many of contemporary participatory or social sensing projects (e.g., Airantzis et al. 2008) could be considered as possible predecessors of components of tomorrow's urban infrastructure. It is well known that people who are marginalized due to economic or other factors are often concentrated in zones 
within the cities that are environmentally degraded, unhealthy, dangerous, and isolated from civic amenities. An 'infrastructure' that monitored air pollution that was mobile and crowd-sourced could serve as alternative watchdog infrastructure that provided evidence that could be used to show that environmental law enforcement was needed.

\subsection{Physical Space}

The actual, palpable, aspects of the city can too be hacked. A demonstration or any other occasion where people take to the streets reconfigures the city if only temporarily. The Occupy Movement (Gamson and Sifry 2013) was a significant expression of this. Another 'hack,' also significant, that is generally motivated more by the need for survival is squatting and the erection of shantytowns, favelas, and informal housing worldwide. The 'Ministry of Space' in Serbia (Predić and Čukić 2013) through semiseriously establishing itself with the quasi-official administrative rhetoric 'Ministry' becomes a 'mirror institution' (Schuler 2008), a provocative hack that could also probably be filed in either the Governance or in the Social, Organizational and Institutional Space dossiers. In the physical space, the Ministry has hacked marquees of shuttered theaters in Belgrade, Serbia ("No Play Tonight. Come Back Yesterday") and 'spontaneously' transformed dismal and neglected urban backwaters into pop-up festivals of music, art, and conviviality. And this can take other forms such as tactical urbanism (Lydon and Garcia 2015), city repair (Cowan et al. 2013), and urban participatory design (DiSalvo et al. 2008). Some types of hacking of the physical space can be promoted by government. The city government in San Francisco, California, has identified 'free spaces' all over the city which people can lease from the city for $\$ 1$ annually. Of course, it is critical to note that physical (as well as other) spaces in the city are often contested and afford unequal access and privilege. This is often maintained through unvoiced norms but often also through laws such as prohibitions against sitting the sidewalk that criminalize poverty. Loukaitou-Sideris and Ehrenfeucht (2009) provide an enlightening look at the history of negotiation and conflict in relation to sidewalks in the USA. Thus, hacking this space often means using the space by people in manners or for purposes that are not formally or informally sanctioned. Henry LeFevre's Rights to the City (1976) provides many insights with which to inform the holistic hacking/civic intelligence orientation. A vast amount of scholarly, political, and activist work has revolved around LeFevre's work. The rights to the city basically focused on the physical/material side of the city, the physical space in our atlas. While this work has been extended in many ways, it could include rights to each of the seven spaces. ${ }^{6}$

\footnotetext{
${ }^{6}$ See the work of Antoniadis and Apostol (2014) on the 'hybrid city' for some 'basics' of the Lefebvre's work.
} 


\subsection{External Space}

Sometimes when hacking the city, it becomes necessary to hack the rest of the world as well. Cities are not autonomous islands or planets but areas that exist within broader environments. These broader environments include the natural world (sometimes forgotten and undervalued) and the inhabitants outside the city (also often forgotten and undervalued) as well as relationships to other cities, towns, and the natural world. This space, of course, is actually a metaspace, although it is listed as a single space for convenience. One way to look at this 'space' would be to see it as a space containing the six others-each of these would be related in various ways to similar spaces 'outside.' This is especially clear in the sense of the governance space; the governance space within a given city has links to other spaces-Seattle's city government, for example, is related to county, state, and federal government as well as to other city governance spaces with a varied set of interrelationships.

Based on his belief that national governments are increasingly unable to promote progressive change, Barber (2013) presents a variety of current and potential relationships between cities in which innovations are spread more quickly and more widely. At the same time, the mayors of the world have established new networks that help them to compare issues and develop innovative approaches to the problems of cities. The C40 Cities Climate Leadership Group (http://www.c40.org/), for example, is a network of the world's megacities committed to addressing climate change.

\subsection{Imaginary Space}

This space may be the most important as it focuses on the creation of 'realities' that are different than the current ones including ones that are actually possible; it drives the conceptual orientation or perspective that people carry in their minds as they move through their daily lives. This space ultimately helps determine how the city and the people within it are represented, basically through narrative imagination about the future - and the present. This is the space of engaged and purposeful makebelieve (Walton 1990). Thinking about the city and its citizens as they are, lays the groundwork for the future: Is the city mysterious, paranoid, engaged, reflective, open, rambunctious, laid-back? This space encourages people to think about what could be and what part they could play in achieving that end. If, for example, they are interested in equity and environmental sustainability and they have sufficient social imagination and self-efficacy, they are more likely to become active advocates (Schuler 2014). If their worldview, on the other hand, consciously or subconsciously, rests on the notion that they are powerless, and change is impossible, then they are more likely to cleave toward the sidelines. If they believe that certain trends and certain types of futures are inevitable, then, again, there is no reason to act beyond the strictly personal and consequently they could decide to concentrate on maximizing personal happiness and material accumulation to the exclusion of everything else. 
This is the space where the idea of play becomes very relevant. Play is rehearsal; it is an occasion for actively exploring possibilities. And the city can be playful; it can support play in an endless number of ways. Playful acts and hacks can be important including novel ones made possible because of digital technologies. The 'Shadowing' project in Bristol, UK, records shadows of people as they pass under a lamp post which are then reproduced for the next person who happens by. This gives the city dweller an unexpected chance to step out of ordinary reality at the very least but also to interact creatively with the system by interacting with the prior shadows or provide new interesting shadows for the next person (Nijholt 2015).

Hacking in this space includes imagining — and articulating — the futures that we'd like to see as well as surfacing the imaginaries that are maintaining or even strengthening harmful tendencies of the status quo (Wright et al. 2013). Neither of these efforts is easy of course. The forces that fight against new ameliorative imaginaries, narratives, and futures are vast; they are seemingly ubiquitous - and they are certainly well-financed. One of the most important aspects of city-making in the imaginary space is that the city that is being constructed is one that won't be in existence for a number of years - if ever. One of the most common contemporary vision of this space is the sustainable city, a city that provides the urban amenities that its dwellers would like to see, to enable them to live within limits in an environment that is a socially responsible entity within itself and with its neighbors and the planet. The 0500 project exemplifies the idea of imagination nudging us into the future. ${ }^{7}$ It demonstrates how large innovative projects are likely to have their origins in the imaginary space:

0500 is a work in progress that aims to foster a global perspective for inventing sustainable urban lifestyles that are compatible with the survival of the biosphere and our aspiration to fulfilled and happy lives. At the same time it is a concrete and immediate action plan based on real projects around the world. ${ }^{8}$

\subsection{Discussion}

Explorations of the city's seven spaces should reveal myriad ways open to citizen engagement and, ultimately, prospects for bringing about positive social change through holistic hacking. Looking at these spaces helps us appreciate the multidimensional richness of the city including how the city is perceived, inhabited, used, imagined, experienced, critiqued, measured, governed, etc., and how cities have changed, are changing, and could change. The framework is abstract, but it takes more specific attributes when it is considered in a specific case. And how the seven spaces are instantiated are not universal-the challenges and opportunities that exist vary considerably according to their context; a hack that is merely frowned upon in one context may be punishable by death in another.

\footnotetext{
${ }^{7}$ http://www.0500.org.

${ }^{8}$ http://www.o500.org.
} 
Each 'space' contains the particular structure linking disparate types of institutions and processes, but like a map, the representation within a space can only represent a portion of the entire space. Hence, uncovering hidden structure and relationships within the space can be crucial. Hacking can take place within a space (or multiple spaces), and it can actually help reconstitute the space (or spaces) and the relationships between them. Although the possibilities for future explorations must be realized in future endeavors, we can at least suggest a number of possible next steps. One of the most interesting that of actual 'maps' or other graphical depictions for the different spaces is suggested by the idea of spaces. This could help people explore the complexity without necessarily overwhelming them. The maps themselves could employ a variety of icons, some specific to a single space, some shared by many, if not all.

\section{Case Study}

The following discussion is based on a recent mobilization that took place in the city of Seattle in the northwest USA but has ramifications beyond. Although this chapter concentrates on city-making, particularly focusing on digital media, I have chosen to convey a broader view of hacking within the seven urban spaces. I have done this for several reasons. The approach that we took to this work was to look at an actual event that was significant yet fairly limited in terms of geography and duration. The objective was to identify an important mobilization and identify what hacks occurred within that-including how new ICT was involved. An alternative approach to exploring city-making vis-a-vis ICT would be to uncover an action that relied to a large degree on ICT. While this approach is certainly valuable, it seems at least possible that it may miss a large part of the reality that it is intended to describe. This includes the fact that movements consist of many moving and, presumably, coordinated elements, some of which takes place online but many offline. Moreover, and this was not demonstrated in this paper, the focus on actions that rely solely on ICT may also miss new constitutive developments or realignments that develop over time.

The hacking spaces framework proposed here relies on the idea that cities are dynamic systems with countless complex, interrelated elements. It does so, however, by presenting spaces that although not strictly autonomous appear to be subject to their own structure, norms, and processes that alter aspects of the city in a broad way that encompasses considerably more than the view of the city as aggregation of people and built structures. Hacking any city attempts to create a city that is an alternative to the current one. But the alternative one is necessarily based on the current one and connected to it; it is not totally separate, and hence, a digital hack that only affected the digital world would not be city-making in the sense that we are exploring. Without a viable connection to the 'real world,' the hack would be impotent. Moreover, the actions (including hacks) that lead to successful conclusions form a dynamic ecosystem. For that reason, in the Shell No example that follows, 
the actions in the spaces that are being discussed are not only digital. On the other hand, because the focus of this chapter and of the book is on digital phenomena, noting the digital as well as the other connections among other actions and across the spaces is critical. The connections between spaces may be bridged via ICT or not (but it is commonly part of the overall campaign). The connections help to form a complete, coherent set of spaces, a universe, although still (of course) inadequately understood.

Cities are made through the activities of people and at the same time the city structures activities of the people. Within the paradigm of the seven spaces, people make cities by changing elements and relationships within those spaces. In the following section, we explore city-making by examining a recent mobilization through the perspectives of the seven spaces. The attempt is to raise a broad number of relevant characteristics without making claims for comprehensive or complete analysis.

\subsection{Shell No}

Climate change is ushering in a new era for the Arctic. The ice is receding at record rates (NSIDC 2012) allowing for unprecedented opportunities for oil extraction. Environmental activists believe that these new efforts endanger the environment and lead to more cataclysmic climate. In the Spring of 2015, Royal Dutch Shell Oil Company was preparing for a new initiative in the Arctic which included docking a giant drilling rig, the Polar Pioneer, at the Port of Seattle. From the point that the rig arrived (14 May 2015) until the point that it departed for its Arctic rendezvous (15 June 2015) environmental activists from Seattle and beyond engaged in holistic hacking, a multiplicity of hackings generally connected to each other-and generally mutually reinforcing - in a variety of non-coerced and semi-autonomous ways.

\section{Information and Communication Space}

Mass media, the modern-day behemoth, was an all-important consideration throughout the duration of the mobilization. All things considered the demonstrations were ultimately mediagenic. The media did not choose to come down hard on the demonstrations. Seattle is progressive politically and is more likely to be environmentally friendly and scientifically informed than other places in the USA. Also, although Seattleites tend to like order they're not strangers to demonstrations. While not focusing on the media alone, the Backbone Campaign, headquartered in the Pacific Northwest, helped ensure that the efforts were clearly recorded in a way that provided a strong message that was interesting enough to catch people's attention and be likely to be picked up by the mass media as well as social media. ${ }^{9}$ Their website stresses 'artful activism,' 'creative action,' and 'building a vibrant and joyous nonviolent nationally networked, community-based progressive populist movement that makes a real and positive difference in people's lives." In addition, the Shell No activists posted to

\footnotetext{
${ }^{9} \mathrm{http} / / /$ www.backbonecampaign.org.
} 
YouTube and managed at least two Facebook accounts which were used for sharing information and ideas, loosely coordinating activities, building community and solidarity, and providing visibility to the cause. Finally, the economic component of this space was also in play. The Port of Seattle makes money from the organizations who use its facilities. And Shell, of course, is a huge corporation that employs people and lobbies government. And economic concerns present a wide variety of hacking opportunities, including boycotts and divestiture.

\section{Governance Space}

As mentioned above, these spaces intersect and interplay in many ways. For one thing, there are many relevant agencies, laws, permits, and the like that govern how-and if - the drilling rig must be managed while it is visiting Seattle's waterways. The permit to allow it to even be there was, in fact, a major contention. It turned out that the discussion and vote on it by the Port Commission was done in secret and there was no public scrutiny (Brownstone Feb 15, 2015a). Clearly having the laws and the roles of the relevant agencies online allowed much more visibility to this space than before.

The Shell No campaign action demonstrates another interesting use of the governance space. On the Polar Pioneer's last day in Seattle, two dozen kayaktivists were arrested as they attempted to block the path of the massive rig (Brownstone Feb 15, 2015b). One protester, Mike O'Brien, was a Seattle City Council member. O'Brien as an elected official brings to mind the governance space. But O'Brien apparently hacked several other spaces as well. By performing civil disobedience, he blurred the line between the governors and the governed and stretched the narrative of what's the proper response to his extraordinary action. In a text message sent from the Coast Guard office while he was being processed, he articulated his objection: "That monstrous rig is headed to the Arctic to attempt to do something unconscionable. I had done everything I know how to do as a citizen, an activist, and as a council member to stop Shell from drilling in the Arctic."

\section{Social, Organizational, and Institutional Space}

In addition to environmental groups such as 350.org and Green Peace, the sovereign nations, indigenous people from North America played strong roles throughout the month of protests. At a basic level, this hacked the legitimacy of the national state and the corporations which is enabled through corporate-friendly legislation. As the original inhabitants, indigenous people have prior rights to the land. However, due to invasion and conquest, they are often impoverished: The environmental damage wrought by modern technologically driven systems is not of their making. It is contrary to their fundamental ethos, yet they are often the ones hit hardest by climate change.

One seemingly unlikely group who played a prominent role was The Raging Grannies, a group of women who dress like 'innocent little old ladies' and were arrested, having padlocked their lawn chairs (with them in them) across the entrance of the port where the rig was docked. They're certainly hacking the 'innocent old lady' paradigm. This group of Grannies was presumably living in the Pacific Northwest although they could have been from any number of affiliated chapters because, 
perhaps unexpectedly, they are a global group and their website Raging Grannies ${ }^{10}$ include a 'herstory' and a 'starter kit' to help other Grannie groups get launched. In addition to people 'of that certain age,' there was also a strong focus at the other end of the age spectrum. Young people were often speakers at the rallies, and some were preteens, while some were in high school or college. Their generation is more likely to be affected by climate change than their predecessors, and in their speeches, they expressed bewilderment that the older generation has been so derelict in its responsibilities to future generations.

\section{Infrastructure Space}

On some level, the entire campaign was focused on infrastructure in a very large sense- the massive worldwide carbon-based enterprise which fuels the economy and unleashes the damaging effects on the planet's climate. Locally, the 400-foot drilling rig presented a visible month-long reminder of this infrastructure, that while huge in itself, is infinitesimal compared to the incomprehensibly vast infrastructure that is being resisted. In marked contrast to the drilling rig, the activists themselves created an alternative structure that also floated in the waters of Puget Sound: A large barge, physically close to the training and embarkation area of the kayaktivists, was used as a music and dancing venue thus providing an opportunity for relaxation and community building under the ever-present shadow of the big rig.

\section{Physical Space}

The physical space of the city is of course important focus of the city. In the Shell No case, this physical space was unlike the typical physical space of cities in general-including Seattle's streets and squares that had been 'hacked' in previous encounters - notably the demonstrations against the US invasion of Iraq in 2003 and against the policies of the World Trade Organization (WTO) in 1999. The physical spaces in the Shell No campaign were to a large degree water-based. A barge, for example, was anchored that served as a floating protest hub and home to music and dance as well. And the water-based space most importantly gave rise to a new breed of protester, the kayaktivists that encircled the rig and attempted to disrupt its northward transit (Fig. 1).

\section{External Space}

While the entire action we are examining took place within Seattle, virtually the entire purpose is tied to situations outside the city limits. The ultimate intent, of course, is to prevent catastrophic effects of climate change. But this can't be accomplished at one go and obviously not by activists in Seattle alone. Other external spaces were involved or incorporated with the Shell No actions. One such transit through this space echoes the movement of the rig itself. Thus, the entire path of moving the rig from one place to another presents opportunities for actions-and cooperation between activist efforts, possibly utilizing the spaces in different ways as the rig moves on-when it enters Canadian waters, for example, and a whole new set of circumstances. Because ultimately the Shell No actions must be linked to other actions outside of the time and space discussed here, the lessons learned in Seattle

\footnotetext{
${ }^{10} \mathrm{http}: / /$ raginggrannies.org.
} 


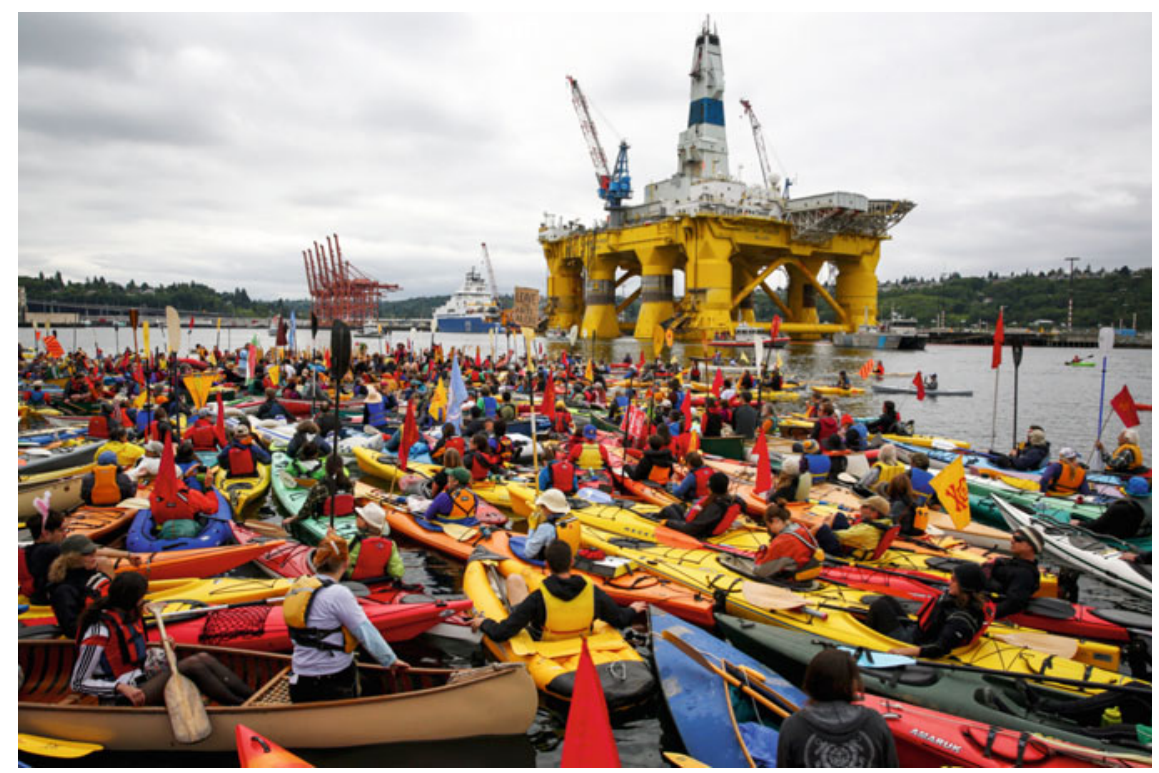

Fig. 1 Hundreds of waterborne kayaktivists demonstrating against shell provide stark contrast to the 400-foot technological behemoth they are resisting. Photograph credit Arctic Drilling Kayaktivists vs Shell Polar Pioneer-Photograph by Daniella Beccaria (https://www.flickr.com/photos/ backbone_campaign/17332349103, Attribution 2.0 Generic (CC BY 2.0))

would ideally be shared with other activists in other locations and the cooperative social networks between them would also grow both quantitatively and qualitatively.

\section{Imaginary Space}

Finally, the imaginary space is also crucial. According to Wright et al. (2013), “... there is a need to view climate change as a social and politically embedded phenomenon, fundamentally linked to patterns of production and consumption and the ideological assumptions that underpin the economic system and our collective sensemaking processes." In other words, climate change presents not only a physical (and ecologically material) threat to our existence but also a conceptual challenge to the way in which we imagine that existence. The Shell No campaign operated in new ways in relation to the imaginary space. One was their ability to encourage new ways of mobilizing people from under-represented sectors (indigenous people, youth, people of color, elderly) in creative, family-friendly events thus helping to legitimize 'protest' by making it more accessible and natural. One of the more prominent ways in which the mobilization used this space resulted in city-making in a way that was abstract yet likely has significant and material consequences. This is by helping to establish Seattle as a site of (inclusive) resistance which could serve as a model. Here, city-making can be city image-making for people within the city and outside the city. This could be part of a broader remaking of cities in general as they become 
increasingly dominant - as well as specific cities, as Dickens did for London and the director Ridley Scott for Los Angeles.

The imaginary space, interestingly, may be the one that reveals changes to the city most clearly. The city itself may have an enlarged activist core and begin, even, to see itself - and be perceived by others as a leader of sorts, whose citizens are active as watchdogs, change agents, and cultivators of civic intelligence.

\section{Hacking the Future}

The nature of the city, currently and in the future, is of critical importance. The main objective of this chapter was to present the seven spaces and to demonstrate why they are important to city-making in an era of ubiquitous networked digital infrastructures. The assertion in this chapter is that changing the nature in one or more of these spaces in a given urban setting (or theater) demonstrates city-making. While the digital domain may quite possibly grow in importance in future campaigns or in some contemporary campaigns, its use in the Shell No campaign was generally supportive (critically so) rather than dominant.

The seven spaces presented here are intended to provide some analytical and design perspective for holistically hacking our future, in particular motivating creative civic intelligence work in the digital realm. The reality is, however, that new concepts or frameworks like new technologies will not do this work for us. That work requires the animating force of human beings, using creativity, values, courage, and intelligence, as well as skilled, reflective, and informed hacking. Also, as noted earlier, blocking these hacking access points, or raising the cost of exploiting them, is threats to democratic processes and the openness of cities as described in the Hackable City Toolkit (2015). One of the most important lessons about civic intelligence is that successful application of civic intelligence increases capacity for applying civic intelligence in future endeavors.

The month-long story of Shell's Polar Pioneer stay in Seattle provides an interesting and useful snapshot, an opportunity to highlight the idea of holistic hacking and the seven spaces in which urban hacking can be enacted. Over the course of the month, two dozen or so formal and informal groups met one or more times a day with a variety of agendas. The coalition was voluntary and informal, and the individual groups usually made their decisions based on consensus. Their actions were always peaceful-if not always legal. The questions as to the effectiveness of their actions are now being raised: "Who won?" is one such question. Clearly, the actions, however brief, attracted national and international attention, e.g., in the UK's Guardian newspaper, and the fight, of course, is not over.

Climate change is still making its global advances while humankind struggles with the issue, sometimes with unprecedented success such as with the Paris agreement in December 2015 but too often with business as usual or even denial. During the writing of this chapter, several months after the main event, Shell abruptly announced that it was ceasing its Arctic operations. After spending over 7 billion dollars (USA) 
on their search, Shell stated that the company had not found enough oil to keep looking (Brownstone 2015c). While the Arctic may be safer in the short term, it is not obvious whether the activists can also claim a win. An organizer from 350 Seattle stated that "I think it's impossible to know which degree we had an impact, but it's safe to say it played into the larger calculus of whether it was worth it to Shell" (Brownstone 2015c).

But the Polar Pioneer may yet return to Seattle (Garnick 2015). The theater will presumably be available. What performances will be enacted there? Will the kayaktivists return, perhaps with new tricks (and hacks) up their sleeves?

This work benefited from discussions with Panayotis Antoniadis, Stephen Buxbaum, Mark Gaved, and Matthew Horwitz. Any mistakes in this analysis or reportage are probably mine.

\section{References}

Aase, Tor H. 1994. Symbolic space: Representations of space in geography and anthropology. Geografiska Annaler. Series B. Human Geography 76 (1): 51-58.

Airantzis, Dimitrios, Alice Angus, Gilles Lane, Karen Martin, George Roussos, and J. Taylor. 2008. Participatory sensing for urban communities. UrbanSense08, 11-15. Raleigh.

Antoniadis, Panayotis, and Ileana Apostol. 2014. The right(s) to the hybrid city and the role of DIY networking. The Journal of Community Informatics 10 (3).

Appadurai, A. 1990. Disjuncture and difference in the global cultural economy. Theory, Culture \& Society 7(2-3): 295-310.

Barber, Benjamin R. 2013. If mayors ruled the world: Dysfunctional nations, rising cities. New Haven: Yale University Press.

Becher, D. 2012. Political moments with long-term consequences. Remaking urban citizenship: Organizations, institutions and the right to the city, 203-220. New Brunswick: Transaction Publishers.

Brooks, Nancy Rivera. 1998. Groups want union oils charter revoked. Los Angeles Times. http:// articles.latimes.com/1998/sep/11/business/fi-21521. Accessed 5 October 2016.

Brownstone, Sydney. 2015a. How Seattle agreed to stash a climate bomb in its seaport. Seattle: The Stranger. http://www.thestranger.com/news/feature/2015/02/25/21780074/how-seattleagreed-to-stash-a-climate-bomb-in-its-seaport. Accessed 10 Oct 2016.

Brownstone, Sydney. 2015b. As the polar pioneer left Seattle this morning, 24 Kayaktivists got detained and fined. Seattle: The Stranger. http://www.thestranger.com/blogs/slog/2015/06/ 15/22391462/as-the-polar-pioneer-left-seattle-this-morning-24-kayaktivists-got-detained-andfined. Accessed 5 Oct 2016.

Brownstone, Sydney. 2015c. Shell is pulling out of the Alaskan Arctic. So what does that mean for Seattle and terminal 5? Seattle: The Stranger. http://www.thestranger.com/blogs/slog/2015/09/ 28/22931976/shell-is-pulling-out-of-the-alaskan-arctic-so-what-does-it-mean-for-seattle-andterminal-5. Accessed 5 Oct 2016.

Buxbaum, S. 2015. Foundations of Governance. The Evergreen State College, April 252015.

Cowan, S., M. Lakeman, J. Leis, D. Lerch, and J.C Semenza. 2013. The city repair project.

de Lange, Michiel, and Martijn de Waal. 2013. Owning the city: New media and citizen engagement in urban design. First Monday, 18 (11).

DiSalvo, Carl, Illah Nourbakhsh, David Holstius, Ayca Akin, and Marti Louw. 2008. The neighborhood networks project: A case study of critical engagement and creative expression through 
participatory design. In Proceedings of the tenth anniversary conference on participatory design 2008, 41-50. Bloomington: ACM.

Gamson, William A., and Micah L. Sifry. 2013. The \#occupy movement: An introduction. The Sociological Quarterly 54 (2): 159-163.

Garnick, C. 2015. Ruling means Shell oil rig could return to city. Seattle Times. September 30. Available at: https://www.seattletimes.com/business/local-business/port-of-seattle-wins-shell-arcticcargo-ruling/. Accessed 5 October 2016.

Guerrilla Girls (Group of Artists). 1998. The Guerrilla Girls' bedside companion to the history of Western art. New York: Penguin Group.

Harvey, D., and M. Davidson. 1973. Social justice and the city. Baltimore: John Hopkins.

Levy, Steven. 2001. Hackers: Heroes of the computer revolution, vol. 4. New York: Penguin Books.

Loukaitou-Sideris, Anastasia, and Renia Ehrenfeucht. 2009. Sidewalks: Conflict and negotiation over public space. Cambridge: MIT Press.

Lotan, Gilad, Erhardt Graeff, Mike Ananny, Devin Gaffney, and Ian Pearce. 2011. The Arab Springl the revolutions were tweeted: Information flows during the 2011 Tunisian and Egyptian revolutions. International Journal of Communication 5.

Lydon, Mike, and Anthony Garcia. 2015. A tactical urbanism how-to. Tactical urbanism, 171-208. Washington: Island Press; Center for Resource Economics.

Hartmann, Björn, Scott Doorley, and Scott R. Klemmer. 2008. Hacking, mashing, gluing: Understanding opportunistic design. IEEE Pervasive Computing 7 (3): 46-54.

Malone, Thomas W., Robert Laubacher, and Chrysanthos Dellarocas. 2009. Harnessing crowds: Mapping the genome of collective intelligence. MIT Sloan School of Management. SSRN. https:// papers.ssrn.com/sol3/papers.cfm?abstract_id=1381502. Accessed 27 July 2018.

Mumford, Lewis. 1996. What is a city? In The city reader, ed. Richard T. LeGates and Freeric Stout, 184-189. London: Routledge.

Nijholt, Anton. 2015. Mischief humor: From games to playable cities. In Proceedings of the 12th international conference on advances in computer entertainment technology. New York: ACM.

NSIDC. 2012. Arctic Sea ice extent settles at record seasonal minimum. National Snow and Ice Data Center. http://nsidc.org/arcticseaicenews/2012/09/arctic-sea-ice-extent-settles-atrecord-seasonal-minimum/. Accessed 5 Oct 2016.

Ostrom, Elinor. 2015. Governing the commons. Cambridge: Cambridge University Press.

Predić, D., and I. Čukić. 2013. Ministarstvo prostora. Belgrade, Serbia: Mikro Art. Available at: https://issuu.com/ministarstvoprostora/docs/ministry_of_space. Accessed 1 September 2016.

Proctor, Robert N., and Londa Schiebinger (eds.). 2008. Agnotology: The making and unmaking of ignorance. Stanford: Stanford University Press.

Robert, Henry M., Sarah Corbin Robert, and Daniel H. Honemann. 2011. Robert's rules of order newly revised. Philadelphia: Da Capo Press.

Schuler, Douglas. 2015. How we may think: The next chapter: Civic intelligence and collective metacognition. ACM SIGCAS Computers and Society 45 (4): 7-14.

Schuler, Douglas. 2014. Pieces of civic intelligence: Towards a capacities framework. E-Learning and Digital Media 11 (5): 518-529.

Schuler, Douglas. 2013. Creating the world citizen parliament. ACM Interactions 20 (3): 38-47.

Schuler, Douglas. 2009. Online civic deliberation with e-liberate. In Online deliberation: Design, research, and practice, ed. Todd Davies, and Seeta Pena Gangadharan, 293-302. Stanford: Csli Lecture Notes.

Schuler, Douglas. 2008. Liberating voices: A pattern language for communication revolution. Cambridge: MIT Press.

Schuler, Douglas. 2001. Cultivating society's civic intelligence: Patterns for a new 'world brain'. Information, Communication and Society 4 (2): 157-181.

Schuler, Douglas. 1996. New community networks: Wired for change. New York: ACM Press, Addison-Wesley Publishing Co. 
Stortone, Stefano, and Fiorella De Cindio. 2015. Hybrid participatory budgeting: Local democratic practices in the digital era. In Citizen's right to the digital city, ed. Marcus Foth, Martin Brynskov, and Timo Ojala, 177-197. Singapore: Springer.

Townsend, Anthony M. 2013. Smart cities: Big data, civic hackers, and the quest for a new utopia. New York: WW Norton \& Company.

von Busch, Otto. 2008. Fashionable. Hacktivism and engaged fashion design. Ph.D. dissertation, University of Gothenburg.

Walton, Kendall L. 1990. Mimesis as make-believe: On the foundations of the representational arts. Cambridge: Harvard University Press.

Weizenbaum, J. 1976. Computer power and human reason: From judgment to calculation. San Francisco: W.H. Freeman and Company.

Wright, Christopher, Daniel Nyberg, Christian De Cock, and Gail Whiteman. 2013. Future imaginings: Organizing in response to climate change. Organization 20 (5): 647-658.

Douglas Schuler With a background in computer science, Doug has spent over three decades looking at opportunities and risks of information and communication systems. Doug has presented his work around the world. In 1987 Doug co-founded the Seattle Community Network, an allvolunteer, free public access computer network. Working with over 85 contributors Doug developed "Liberating Voices, a pattern language for communication revolution", that is available as a book and is online in five languages. He also wrote New Community Networks, co-edited six books, and authored dozens of articles and book chapters. Doug is former chair of Computer Professionals for Social Responsibility. He directs the Public Sphere Project and is working on projects such as eLiberate, an online application that supports distributed meetings using Roberts Rules of Order. Doug is continuing to explore civic intelligence, the collective capability of society to address its problems, with his teaching, research, and organizing.

Open Access This chapter is licensed under the terms of the Creative Commons Attribution 4.0 International License (http://creativecommons.org/licenses/by/4.0/), which permits use, sharing, adaptation, distribution and reproduction in any medium or format, as long as you give appropriate credit to the original author(s) and the source, provide a link to the Creative Commons license and indicate if changes were made.

The images or other third party material in this chapter are included in the chapter's Creative Commons license, unless indicated otherwise in a credit line to the material. If material is not included in the chapter's Creative Commons license and your intended use is not permitted by statutory regulation or exceeds the permitted use, you will need to obtain permission directly from the copyright holder.

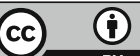

